\title{
Doctor: Why Has Her Urine Turned Purple?
}

\author{
María García-López ${ }^{1}$, Carlos Cárceles-García², Mariya Ovsepyan², Jara Llenas-García ${ }^{1}$ \\ ${ }^{1}$ Internal Medicine Department, Vega Baja Hospital, Orihuela, Spain \\ ${ }^{2}$ Emergency Medicine Department, Vega Baja Hospital, Orihuela, Spain
}

Received: 20/09/2016

Accepted: 04/10/2016

Published: 18/09/2016

How to cite this article: García-López M, Cárceles-García C, Ovsepyan M, Llenas-García J. Doctor: why has her urine turned purple? EJCRIM 2016;3: doi:10.12890/2016_000507.

Conflicts of Interests: The Authors declare that there are no competing interests.

This article is licensed under a Commons Attribution Non-Commercial 4.0 License

\section{ABSTRACT}

We present the case of an elderly woman with long-term indwelling urinary catheter use whose urine turned purple due to a urinary tract infection.

\section{LEARNING POINTS}

- Purple urine bag syndrome is secondary to urinary tract infections with indigo- and indirubin-producing bacteria and affects typically institutionalized and chronically catheterized patients.

- Escherichia coli, Citrobacter and Proteus spp are the main culprit.

- It may reflect only asymptomatic bacteriuria and therefore the need for antibiotic treatment must be carefully addressed and individualized.

- Catheter sanitation, constipation avoidance and prompt removal of unnecessary catheters are key to prevention.

\section{KEYWORDS}

Purple urine bag syndrome; urinary catheterization; urinary tract infections; indigo; indirubin

\section{CASE DESCRIPTION}

A 90-year-old woman with advanced dementia and prolonged urinary catheterization presented to the emergency department with general discomfort. Her relatives described her urine's color turning purple ten days prior. Her medical history was remarkable for type 2 DM, chronic kidney disease (CKD), cardiovascular disease and recurrent urinary tract infections (UTIs). On physical examination, the urine in her Foley tubing and bag was bright purple (Fig. 1). C-reactive protein in blood was $12 \cdot 7 \mathrm{mg} / \mathrm{dL}$ (normal<1). Her urine was alkaline (pH 8 ). Empiric ceftriaxone and intravenous fluids were started. Within 24 hours, her condition improved and urine color returned to normal (Fig. 2). The urine culture grew $>100,000$ UFC/mL Citrobacter freundii and Enterococcus spp.

\section{DISCUSSION}

Purple urine bag syndrome (PUBS) is a condition in which the urine bag and tubing of chronically catheterized patients turn purple. It is secondary to UTIs with indigo- and indirubin-producing bacteria ${ }^{[1]}$, most commonly Escherichia coli, Citrobacter spp or Proteus spp ${ }^{[2,3]}$. Dietary tryptophan is metabolized to indole by gastro-intestinal bacteria and then converted to indole-sulfate in the liver. Certain bacteria possess enzymes which catalyze indole-sulfate, finally producing indirubin (red) and indigo (blue) that then concentrate in the urine, producing an 
intense purple color ${ }^{[1]}$. A similar phenomenon has been described in infants born with a genetic metabolic disorder called Drummond's Syndrome or blue diaper syndrome, a rare inborn error metabolism. Drummond's Syndrome is characterized by the incomplete intestinal breakdown and absorption of tryptophan that is then metabolized to indoles, absorbed and then excreted in the urine, which becomes stained in blue on infant's diapers (indoluria) ${ }^{[4]}$.

Female gender, dementia, chronic debilitated states, alkaline urine, constipation, high bacterial loads and CKD are risk factors for PUBS[2,3], and this syndrome is more frequently reported in Asian patients. PUBS is generally benign but distressing for caregivers and unfamiliar health providers; aggressive management with antibiotics is generally not advised ${ }^{[3]}$. Conversely, catheter sanitation and hygienic and nutritional measures to avoid constipation must be carefully addressed. Institutional policies of prompt recognition of unnecessary indwelling catheters and their removal are needed; multimodal interventions that include staff education and training, daily patient tracking or electronic alerts may help ${ }^{[5]}$. Novel silver-impregnated Foley catheter systems or hydrogel catheters pretreated with a phage cocktail may play a future role in PUBS prevention ${ }^{[6]}$.

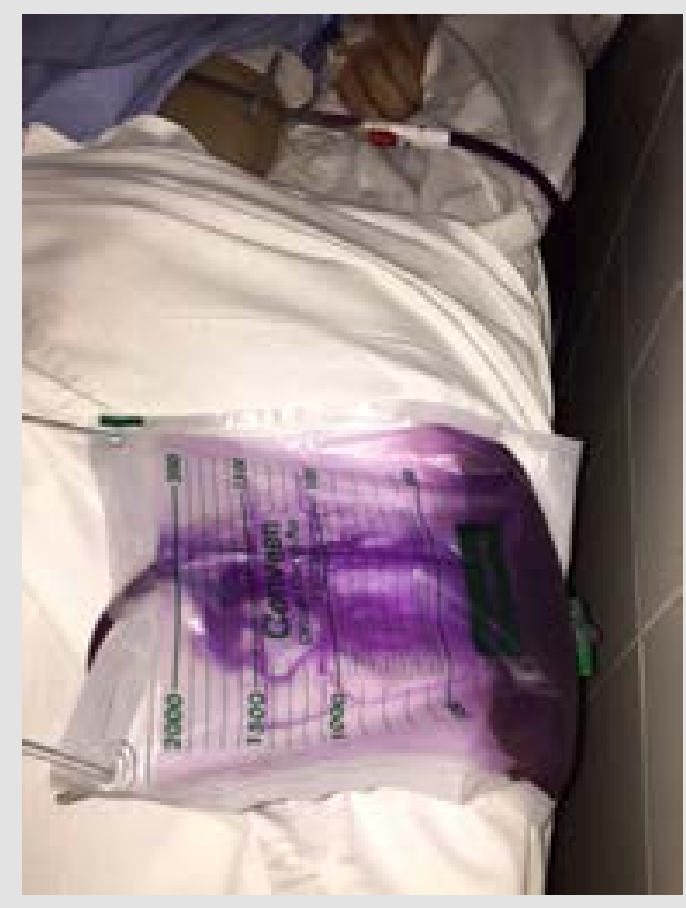

Figure 1: Patient's urine at admission

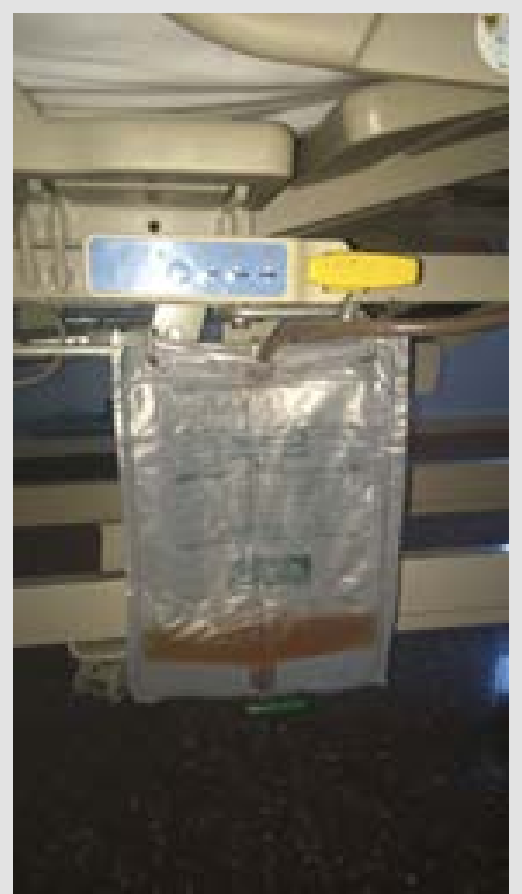

Figure 2: Patient's urine 24 hours after treatment initiation

\section{REFERENCES}

1. Khan F, Chaudhry MA, Qureshi N, Cowley B. Purple urine bag syndrome: an alarming hue? A brief review of the literature. Int J Nephrol 2011;2011:419213.

2. Mantani N, Ochiai H, Imanishi N, Kogure T, Terasawa K, Tamura J. A case-control study of purple urine bag syndrome in geriatric wards. J Infect Chemother 2003;9:53-7.

3. Hadano Y, Shimizu T, Takada S, Inoue T, Sorano S. An update on purple urine bag syndrome. Int J Gen Med 2012;5:707-10.

4. Drummond K, Michael A, Ulstrom R, Good R. The blue diaper syndrome: familial hypercalcemia with nephrocalcinosis and indicanuria; a new familial disease, with definition of the metabolic abnormality. Am J Med 1964;37:928-48.

5. Mody L, Krein SL, Saint S, Min LC, Montoya A, Lansing B, et al. A targeted infection prevention intervention in nursing home residents with indwelling devices: a randomized clinical trial. JAMA Intern Med 2015;175:714-23.

6. Lehman SM, Donlan RM. Bacteriophage-mediated control of a two-species biofilm formed by microorganisms causing catheter-associated urinary tract infections in an in vitro urinary catheter model. Antimicrob Agents Chemother 2015;59:1127-37. 